\title{
NILAI PENDIDIKAN AGAMA HINDU DALAM CERITA PERGURUAN SANG ARUNIKA, SANG UTAMANYU, DAN SANG WEDA KEPADA BHAGAWAN DHOMYA
}

\author{
I WAYAN DAUH \\ FAKULTAS ILMU AGAMA DAN KEBUDAYAAN \\ UNIVERSITAS HINDU INDONESIA
}

\begin{abstract}
ABSTRAK
Pendidikan merupakan sebuah proses di mana manusia memperoleh pengajaran untuk meningkatkan kemampuannya dalam menjalankan kehidupan. Dalam proses pendidikan, peran guru tidak saja mentransfer ilmu pengetahuan kepada siswanya, tetapi lebih pada pembentukan sikap, moral, dan pribadi yang luhur terhadap siswa. Tuntunan ajaran agama Hindu banyak sekali dituangkan dalam konsep cerita karena pendidikan agama Hindu sesungguhnya dari dulu telah mengusahakan pendidikan kepada siswa dengan menyeimbangkan aspek jasmani dan rohani. Salah satu ajaran tata susila yang ada dalam ajaran agama Hindu adalah ajaran yang terkandung dalam cerita "Bhagawan Dhomya". Cerita Bhagawan Dhomya merupakan cerita yang banyak mengandung nilainilai pendidikan yang mampu dijadikan pedoman atau pegangan pada masa (tahapan) berguru baik sebagai siswa dan guru, karena mengingat penyelenggaraan pendidikan terhadap tingkah laku siswa di zaman sekarang yang semakin cenderung menurun.
\end{abstract}

Kata kunci: Nilai, Pendidikan Agama Hindu, Cerita

\section{ABSTRACT}

Education is a process by which human beings acquire teaching to enhance their abilities in running their life. In the process of education, the roles of the teachers are not just transferring knowledge to their students, but more on the formation of attitudes, moral, personal and sublime to the students. The guiding tenets of Hindu religion once poured in the concept of the story because of the Hindu religious education had been aiming at education to students with a balance of physical and spiritual aspects. One of the tenets of decency that is present in the teachings of Hinduism is the teaching which contained in the Bhagavan Dhomya story. It is a story that contains a lot of education values that are able to handle or the guidelines used in the (stage) college's period both as students and teachers, because considering the Organization of the education of student's behavior during the college's period which increasingly tend to decrease.

Keywords: value, Hinduism education, story.

\section{PENDAHULUAN}

Karya sastra klasik (tradisional) yang berbentuk cerita, gaguritan, lontar maupun karya sastra klasik lainnya memiliki hubungan yang sangat erat dengan ajaran agama Hindu. Melalui sastra para seniman mendapat ide-ide dan imajinasi untuk menciptakan kreasi-kreasi baru dalam berbagai kesenian, baik dalam seni lukis, seni suara, seni tari dan seni lainnya. Seni 
budaya Bali sudah mengakar dalam kehidupan beragama yang menjiwai seluruh kegiatan seni budaya (Utama, 2011:66). Hal ini dapat dilihat dari hampir tidak ada satupun kegiatan upacara agama Hindu yang selesai tanpa ikut sertanya suatu pertunjukan kesenian.

Gaguritan adalah salah satu karya sastra klasik yang di dalamnya tersirat ajaran-ajaran, nilai-nilai pendidikan agama Hindu dan banyak mencerminkan nilai-nilai yang berhubungan dengan aspek kehidupan sehari-hari. Gaguritan merupakan salah satu karya klasik (tradisional) yang unik karena memiliki suatu ikatan dan konvensi sastra. Sistem konvensi sastra tersebut, disebabkan oleh adanya syaratsyarat pupuh yang mengikatnya disebut padalingsa. Padalingsa terdiri dari dua kata, yaitu pada dan lingsa, pada berarti banyaknya bilangan suku kata dalam satu baris atau carik, sedangkan lingsa adalah bunyi akhir masing-masing dalam satu bait (Agastya,1980:17). Oleh karena itu dalam penciptaan gaguritan, pupuhlah yang menjadi dasarnya, sehingga dikatakan, bahwa sebuah gaguritan harus minimal memiliki pupuh dalam satu ceritanya.

Selain pupuh, bahasa juga diperhitungkan oleh seorang pengarang untuk menyusun ide-ide dalam sebuah karya sastra gaguritan. Bahasa yang biasanya digunakan dalam gaguritan sebagai media adalah Bahasa Bali Kepara (Bahasa Bali lumrah) dan Bahasa Bali Kawi. Diantara kedua bahasa tersebut, Bahasa Bali Kepara yang lebih dominan dipakai dalam gaguritan (Tingen, 1986:12). Selain itu ada juga gaguritan yang terdapat unsur prosanya, sehingga karya sastra gaguritan dikatakan sebagai karya sastra yang memiliki struktur naratif (puisi yang mengandung cerita).

Karya sastra gaguritan mempunyai peranan penting dalam usaha pembinaan mental dan spiritual masyarakat Bali pada umumnya (Agastya, 1980:25). Suatu hal yang patut dibanggakan yaitu betapa hebatnya para pujangga jaman dahulu yang mampu menuangkang isi pikiran lewat karya sastranya yang indah dan banyak memberikan tuntunan atau pengetahuan di dalam kehidupan beragama. Karya-karya sastra tersebut disamping sebagai sumber ilmu pengetahuan, juga di kalangan tertentu masih dipertahankan sebagai warisan yang disakralkan (Madera,1997). Sebagai karya sastra klasik yang banyak mengandung nilai-nilai agama, maka gaguritan sangat perlu untuk diikaji atau diteliti agar dapat mengetahui dan memahami nilai-nilai dan ajaran-ajaran yang terdapat dalam gaguritan tersebut.

Mengingat banyaknya karya sastra klasik dalam bentuk gaguritan tersebut, maka penulis ingin mengkaji salah satu karya sastra berupa gaguritan yang berjudul "Dang Guru Bhagawan Dhomya”. Gaguritan Dang Guru Bhagawan Dhomya tidak hanya indah dalam struktur narasi, namun yang paling penting ialah intisari nilai-nilai pendidikan agama dan pokok-pokok ajaran agama Hindu yang terkandung didalamnya. Nilai-nilai tersebut sangat penting dan berguna sebagai landasan berpijak dan sebagai pedoman dalam berbuat dan bertingkah laku yang baik dan benar sesuai dengan ajaran agama.

Melalui pengupasan dan meempelajari langsung intisari Gaguritan Dang Guru Bhagawan Dhomya, maka diharapkan dapat memotivasi serta menuntun sikap ke 
arah kebajikan dan kesempurnaan hidup lahir dan batin, terutama bagi masyarakat dan generasi muda yang kurang pengeetahuannya dan bahkan yang menganggap bahwa gaguritan merupakan cerita rakyat yang sudah ketinggalan jaman dan tidak pelu diteruskan kepada generasi berikutnya (Agastya,1982:3).

Nilai-nilai luhur dalam Gaguritan Dang Guru Bhagawan Dhomya sanagat penting sehingga perlu dikaji dan diperkenalkan kepada masyarakat umat Hindu. Tujuannya agar lebih mudah dapat dipakai sebagai pedoman untuk dihayati dan diamalkan dalam kehidupan sehari-hari, serta selanjutnya tetap dijaga lestarinya karya sastra klasik dalam bentuk gaguritan, khususnya dalam Gaguritan Dang Guru Bhagawan Dhomya. Atas dasar pertimbangan tersebut, maka penulis tertarik untuk menulis karya tulis dengan judul "Kajian Pendidikan Agama Hindu Dalam Gaguritan Dang Guru Bhagawan Dhomya”.

\section{PEMBAHASAN}

\section{Karmaphala Sradha}

Dalam agama hindu terdapat lima keyakinan atau kepercayaann disebut Panca Sradha, yaitu Widhi Sradha, Atma Sradha, Karmaphala Sradha, Punarbhawa Sraddha dan Moksha Sradha. Dalam Gaguritan Dang Guru Bhagawan Dhomya yang lebih ditekankan dari kelima sradha itu adalah Karmaphala Sradha saja. Pada semua sisyanya yang diuji itu terdapat ajaran Karmaphala Sradha. Karmaphala terdiri dari dua kata yaitu Karma dan Phala. Karma artinya perbuatan dan Phala artinya hasil, jadi Karmaphala berarti hasil dari perbuatan dari seseorang (Sukartha, 2004:16).
Ajaran Karmaphala merupakan salah satu bagian dari ajaran Panca Sradha. Setiap umat Hindu percaya bahwa setiap perbuatan baik (Subha Karma) akan mendatangkan hasil yang baik pula dan sebaliknya perbuatan buruk (Asubha Karma) akan mendatangkan hasil yang buruk pula. Dengan adanya hukum Karmaphala ini dapat membawa keyakinan kepada seluruh umat Hindu untuk selalu berbuat dan bertingkah laku berdasarkan susila atau etika yang baik. Karmaphala merupakan hukum sebab akibat yang bersifat mutlak, karena bersumber dari hukum Tuhan. Dalam ajaran Agama Hindu ada tiga jenis Karmaphala yaitu Sancita Karmaphala adalah hasil perbuatan pada masa kehidupan lampau, apa yang belum habis dinikmati pada waktu itu menjadi benih yang menentukan kehidupannya sekarang. Prarabdha Karmaphala adalah hasil perbuatan pada waktu sekarang dinikmati sekarang juga. Kryamana Karmaphala adalah hasil perbuatan sekarang dan tidak sempat dinikmati, maka harus dinikmati mada kehidupan yang akan datang (Kemenuh, 1983:18). Dengan demikian, cepat atau lambat baik dalam kehidupan sekarang maupun masa yang akan datang, segala phala dari perbuatan itu pasti akan diterima, karena sudah merupakan hukum Tuhan.

Dalam Gaguritan Dang Guru
Bhagawan Dhomya, Prarabda
Karmaphala yang banyak didapatkan
oleh semua sisyanya, karena ini
merupakan hasil ujian dalam upaya
melaksanakan perbuatan yang
ditugaskan oleh Dang Guru untuk
menguji kemampuan dari masing-
masing sisyanya. Akan hal ini
dinyatakan sebagai berikut:

Dalam Gaguritan Dang Guru Bhagawan Dhomya, Prarabda Karmaphala yang banyak didapatkan oleh semua sisyanya, karena ini merupakan hasil ujian dalam upaya melaksanakan perbuatan yang ditugaskan oleh Dang Guru untuk menguji kemampuan dari masingdinyatakan sebagai berikut: 
"Daweg ngawit matanduran, Binihnyane becik mentik, Tedun Sabeh bales pisan, Ngardi pundukane rubuh, Ajrih tandurane usak, Katetehin, Ragane kanggen ngempelan”.

(Gaguritan Dang Guru Bhagawan Dhomya, Pupuh Ginada nomor 3 halaman 40).

"Lemah peteng kaempelang, Dang Guru Ida nyiingakin, Ring Arunika kapica, Antuk baktinyanē langkung, Uddalaka kicen parab, Cening molih, Bagia ne lakar temuang"

(Gaguritan Dang Guru Bhagawan Dhomya, Pupuh Ginada nomor 4 halaman 41-42).

\section{Terjemahannya:}

"Ketika mulai menanam, bibit yang ditanam baik sekali tumbuhnya tetapi secara tiba-tiba turun hujan yang sangat lebat, menyebabkan pematang sawah menjadi roboh. Takut tanamannya menjadi rusak, lalu pematang sawah itu ditindih dengan memakai badannya untuk menahan dan membendungnya". "Siang dang malam pematang sawah yang digenangi air hujan itu dibendung dengan badannya, Dang Guru sebagai penguji menyaksikan kejadian itu, lalu kepada Sang Arunika diberikan hadiah, berdasarkan pada baktinya kepada Dang Guru melebihi, diberikan nama Uddalaka, kamu berhasil, dan akan menemukan kebahagiaan".

Karmaphala yang di dapatkan oleh Sang Arunika merupakan Prarabda Karmaphala yaitu hasil perbuatan sekarang yang disebatkan oleh perbuatannya dinikmati juga di waktu kehidupan sekarang, ini dibuktikan dengan Dang Guru melihat langsung Sang Arunika begitu bhaktinya rela menjadikan tubuhnya sebagai penghalang air karenan pematang sawah hancer karena banjir agar tanamannya tidak tergenang air langsung Dang Guru menyuruh Sang Arunika untuk bangun dan langsung diberikan hadiah dan gelar yaitu Uddalaka.

\section{Berikutnya}

Prarabda

Karmaphala juga didapatkan oleh Sang Utamanyu, tetapi dalam tugasnya memang lebih banyak namun dalam melaksakan tugasnya tersebut tetap disiplin, gigih, tulus, ikhlas dan apabila melakukan kesalahan dan diberi saran oleh Dang Guru, Sang Utamanyu cepat memohon maaf. Hal-hal yang telah dilakukan itu dinilai keliru atau salah seperti untuk memenuhi rasa laparnya mengembalakan lembu karena tidak membawa persiapan bekal untuk dimakan, Sang Utamanyu pun melakukan perbuatan seperti: pertama meminta-minta, hasil dari memintanya itu dimakan sendiri tidak dihaturkan kepada Dang Guru. Perbuatan ke dua yang diakukan lagi meminta-minta, tetapi apa yang didapatkan semuanya dihaturkan kepada Dang Guru juga tidak dibenarkan karena itu perbuatan loba. Selanjutnya pada perbuatan ke tiga ditanyai oleh Dang Guru dengan jujur dijawab, bahwa yang dimakan adalah didih-didih susu yang jatuh ketanah sisa-sisa dari anak lembu juga tidak dibenarkan oleh Dang Guru karena itu sama saja mengambil hak orang lain. Untuk menahan rasa laparnya Sang Utamanyu meminum getah pohon Medori yang rupanya hampir sama dengan susu, setelah meminum getah tersebut seketika badannya terasa panas dan membuat ia buta.

Akhirnya lembu yang digembalakan tersebut kemmbali kekandangnya sendiri-sendiri dan Sang Utamanyu tidak terlihat mengantarkan. 
Dang Guru akhirnya pergi menyelidiki kesana-kemari untuk menemukan Sang Arunika dan pada keesokan harinya ditemukan berada di dalam sumur, lalu Dang Guru bertama bagaimana bisa sampai begini. Utamanyu pun menceritakan kejadian yang sebenarnya, hingga Dang Guru merasa sedih setelah mendengarkan cerita dari Utamanyu tersebut, Dang Guru menganugrahkan Mantra Tamba Utama dari Dewa Aswino untuk menghilangkan buta matanya berdasarkan rasa bakti, tulus ikhlas dan tidak gampang menyerah dalam melaksanakan tugas yang diberikan. Dinyatakan sebagai berikut:

"Wus kapica, Utamanyu sida eling, Mantra Sidhi ngucap, Tur sida anggen ngubadin, Tan sida mangawe wredha".

(Gaguritan Dang Guru Bhagawan Dhomya, Pupuh Maskumambang nomor 16 halaman 53).

\section{Terjemahannya:}

"Utamanyu setelah diobati dengan anugran Mantra Tamba Utama, dengan segera ingat dan butanya hilang, selain dapat dinakan untuk mengoobati mantra tersebut juga bisa mengakibatkan awet muda".

Berikutnya juga Prarabda Karma Phala diperoleh oleh muridnya yang ke tiga yaitu Sang Weda yang diuji dengan tugas membuat makanan di dapur dan mampu dengan baik melaksanakaan tugas tersebut. Setelah itu diberikan anugrah berupa mantra Weda yang utama. Akan hal ini dinyatakan sebagai berikut:

"Glantur mangkin katureksa, Sang Weda sisya ping tri, Kicen ngaryanang rayunan, Sida ne becik kakardi, Tuntunan Guru Katinutin, Mawinan kicen pangweruh, Mantra
Weda mautama, Mlarapan pakardi becik wus punika, Sang Weda mawali budal".

(Gaguritan Dang Guru Bhagawan Dhomya, Pupuh Sinom nomor 17 halaman 53-54).

\section{Terjemahannya:}

"Sekarang dilanjutkan menguji, Sang Weda muridnya yang ke tiga, diberikan tugas untuk memmbuat makanan, Sang Weda melakukan dengan baik, petunjuk Dang Guru diikutinya, menyebabkan Sang Weda diberi kepandaian berupa Mantra Weda yang utama, berdasarkan atas hasil pembuatan makanannya dinilai baik, setelah selesai dinilai Sang Weda mohon diri untuk pulang".

Demikianlah pada akhirnya ke tiga orang sisya Dang Guru Bhagawan Dhomya telah berhasil mendapatkan Prarabdha Karmaphala, yaitu haasil perbuatan pada waktu kehidupan sekarang dinikmati pula pada waktu sekarang juga.

\section{Ajaran Susila (etika) dalam Gaguritan Dang Guru Bhagawan Dhomya}

Ajaran Susila atau etika Hindu termuat di dalam Weda yang bersifat kekal abadi, semenjak diturunkan samapai saat ini dan demikian seterusnya. Kata susila berasal dari bahasa Sansekerta, yaitu su yang artinya baik dan sila artinya tingkah laku, jadi susila adalah tingkah laku yang baik (Tim, 2005:122). Di dalam bertingkah laku seseorang haarus benarbenar dapat memilah mana perbuatan yang patut untuk dilaksanakan dan mana perbuatan yang tidak patut untuk dilaksanakan. Susila atau etika adalah nilai-nilai dan norma-norma moral yang 
menjadi pedoman bagi seseorang atau kelompok dalam mengatur tingkah lakunya, etika berkaitan dengan nilai, norma dan moral (Atmaja, 2010:3).

Terkait dengan pengertian etika atau susila yang telah dipaparkan di atas, maka dalam Gaguritan Dang Guru Bhagawan terdapat nilai etika atau susila, namun yang paling menonjol adalah ajaran Tri Kaya Parisudha.

\section{Ajaran Tri Kaya Parisudha dalam Gaguritan Dang Guru Bhagawan Dhomya}

Terkait dengan nilai susila atau etika dalam Gaguritan Dang Guru Bhagawan Dhomya, mengandung ajaran etika yang diwujudkan dalam ajaran Tri Kaya Parisudha. Menurut Lodera (2008:25), ajaran Tri Kaya Parisudha merupakan ajaran tata susila, etika dan moral dalam agama Hindu yang telah diyakini, bahwa suatu perbuatan manusia berlandaskan tiga hal yang terdapat dalam pembagian Tri Kaya Parisudha yaitu Manacika, Wacika dan Kayika.

Atmaja (2010:70) menyebutkan bahwa Manacika adalah pikiran, Wacika adalah perkataan dan Kayika adalah perbuatan. Sebagai umat Hindu, dituntun untuk berkewajiban untuk dapat berpikir yang baik dan benar, berkata atau dapat berpikir yang baik dan benar serta berbuat yang baik dan benar.

Berdasarkan pengertian diatas, Tri Kaya Parisudha adalah ajaran yang selalu menuntut umat Hindu agar berpikir yang baik dan benar terlebih dulu setelah itu baru berkata dan berbuat yang baik karena segala perkataan dan perbuatan pasti berawal dari pikiran, pikiran yang baik akan berpengaruh juga terhadap perbuatan yanng baik pula. Akibatnya sisya-sisya Dang Guru Bhagawan Dhomya menjadi mampu mengendalikan diri, sehingga dalam menempuh ujian semuanya mendapatkan hasil yang baik dan tidak ada tertunda. Upaya pengendalian diri tersebut terwujud dalam perilaku pasa sisyanya selalu mengikuti peeetunjuk, arahan, tuntunan dari Dang Guru, sehingga menjadi disiplin, taat, waspada dalam mengikuti ujian yang dihadapi dengan sikap dan perbuatan yang baik. Ini tercermin dalam bait Gaguritan Dang Guru Bhagawan Dhomya sebagai berikut:

"Daweg ngawit matanduran, Binihnyane becik mentik, Tedun Sabeh bales pisan, Ngardi pundukane rubuh, Ajrih tandurane usak, Katetehin, Ragane kanggen ngempelan”.

(Gaguritan Dang Guru Bhagawan Dhomya, Pupuh Ginada nomor 3 halaman 40).

"Nglantur ring Utamanyu, Sisyan Ida ne ping kalih, Ngangon lembu swadharmanya, Becik pisan klaksanain, Jantos tan eling manunas, Ngawe kluwen karasanin".

(Gaguritan Dang Guru Bhagawan Dhomya, Pupuh Ginanti nomor 5 halaman 43).

"Glantur mangkin katureksa, Sang Weda sisya ping tri, Kicen ngaryanang rayunan, Sida ne becik kakardi, Tuntunan Guru Katinutin, Mawinan kicen pangweruh, Mantra Weda mautama, Mlarapan pakardi becik wus punika, Sang Weda mawali budal".

(Gaguritan Dang Guru Bhagawan Dhomya, Pupuh Sinom nomor 17 halaman 53-54). 


\section{Terjemahannya:}

"Pada saat mulai menanam bibit, bibitnya itu tumbuh dengan baik, tibatiba hujan lebat, menyebabkan pematang sawah menjadi roboh, Sang Arunika takut benih yang telah ditanam itu menjadi rusak, lalu pematang sawahnya itu ditindih, badannya Sang Arunika dipakai membendung air hujan itu".

"Dilanjutkan pengujian pada Sang Utamanyu, murid beliau Dang Guru yang kedua, diberikan tugas untruk mengembalakan lembu, tugasnya tersebut dilaksanakan dengan baik, sampai lupa makan, menyebabkan perutnya terasa lapar".

"Sekarang dilanjutkan menguji, Sang Weda muridnya yang ke tiga, diberikan tugas untuk memmbuat makanan, Sang Weda melakukan dengan baik, petunjuk Dang Guru diikutinya, menyebabkan Sang Weda diberi kepandaian berupa Mantra Weda yang utama, berdasarkan atas hasil pembuatan makanannya dinilai baik, setelah selesai dinilai Sang Weda mohon diri untuk pulang".

Berdasarkan uraian di atas tentang ajaran-ajaran agama Hindu dalam Gaguritan Dang Guru Bhagawan Dhomya dan hasil dari wawancara peneliti dapat simpulkan bahwa ajaranajaran agama Hindu yang terkandung yaitu ajaran Tattwa yang lebih menekankan kepada ajaran Karmaphala dimana kita diajarkan bagaimana berbuat yang baik agar mendapat hasil yang baik juga dan ajaran Susila (etika) yang menekankan pada ajaran Tri Kaya Parisudha yaitu bagaimana kita diajarkan bepikir, berkata dan berbuat yang baik (Manacika, Wacika dan
Kayika) guna dapat menjalani kehidupan dengan baik.

\section{Nilai Pendidikan Agama Hindu dalam Gaguritan Dang Guru Bhagawan Dhomya}

Pendidikan agama Hindu pada hakekatnya adalah suatu sistem pendidikan yang berpijak pada ajaranajaran agama Hindu dengan kitab suci Weda sebagai acuan atau pedomannya. Weda diyakini dan dipedomani oleh umat Hindu sebagai satu-satunya sumber bimbingan dalam kehidupan sehari-hari ataupun dalam melakukan pekerjaan-pekerjaan tertentu (Pudja, 1985:1).

Berdasarkan beberapa pendapat di atas, dapat disimpulkan bahwa nilai pendidikan agama hindu adalah sesuatu yang berharga dan berkualitas yang merangkum keseluruhan ajaran-ajaran agama Hindu dalam bentuk sistem pendidikan sebagai petunjuk dan arahan yang positif dalam menjalani kehidupan ini dan selalumengarahkan agar selalu berbuat baik dengan berlandaskan dharma dan berpedoman pada kitab suci Weda. Sehubungan dengan hal tersebut, maka nilai pendidikan agama Hindu yang terdapat dalam Gaguritan Dang Guru Bhagawan Dhomya adalah sebagai berikut:

\section{a) Nilai Pendidikan Asthiti Bakti}

Sudah menjadi kewajiban bagi seorang sisya atau murid yang telah dididik oleh Dang Guru Bhagawan Dhomya dan telah dipandang selesai mengikuti didikannya patut mendapatkan pemeriksaan melalui ujian untuk mengetahui kemampuan dari siswanya tersebut. 
Hal tersebut tercermin dari bait Gaguritan Dang Guru Bhagawan Dhomya berikut ini dimana peneliti hanya mengambil pokok-pokok Gaguritan tersebut karena sudah sangat jelas keseluruhan isi Gaguritan Dang Guru Bhagawan Dhomya dijelaskan pada alur:

"Arunika kapartama, Indik swadharmanē yukti, Tutut bakti nē mangemban, Daging piteket Dang Guru, Polih makarya ring sawah, Sayuwakti, Waspada pisan makarya".

(Gaguritan Dang Guru Bhagawan Dhomya, Pupuh Ginada nomor 2, halaman 39-40).

"Nglantur ring Utamanyu, Sisyan Ida $n \bar{e}$ ping kalih, Nngangon lembu Swadharmanya, Becik pisan klaksanain, Jantos tan eling manunas, Ngawē kluwēn karasanin".

(Gaguritan Dang Guru Bhagawan Dhomya, Pupuh Ginanti nomer 5, halaman 43).

"Glantur mangkin katureksa, Sang Weda sisya ping tri, Kicen ngaryanang rayunan, Sida ne becik kakardi, Tuntunan Guru Katinutin, Mawinan kicen pangweruh, Mantra Weda mautama, Mlarapan pakardi becik wus punika, Sang Weda mawali budal”.

(Gaguritan Dang Guru Bhagawan Dhomya, Pupuh Sinom nomor 17 halaman 53-54).

"Daging gatra ne punika, Mangda Sang Weda mangiring, Sapatuduh Guru Dhomya, Ngemit pasramane jati, sareng sadagingin puri Sang Weda manunas tulung, Ring sisyane Sang Utangka, Sane malaksana ngemit sapatuduh, Sang Utangka las ngiringang".
(Gaguritan Dang Guru Bhagawan Dhomya, Pupuh Sinom nomor 19 halaman 56-57).

\section{Terjemahannya:}

"Muridnya yang diuji pertama adalah Sang Arunika, dalam tugasnya mengikuti petunjuk Dang Guru dengan baik. Sang Arunika diuji bekerja disawah sebagai petani, benar-benar berhati-hati dan waspada dalam mengerjakannya".

"Dilanjutkan melaksanakan ujian pada Sang Utamanyu, murid beliau Dang Guru Bhagawan Dhomya yang kedua, diberi tugas untuk mengembalakan lembu, tugasnya itu dilaksanakan dengan baik sekali, sampai sang Utamanyu lupa makan, yang menyebabkan rasa lapar dirasakan oleh perutnya".

"Sekarang dilanjutkan menguji, Sang Weda muridnya yang ke tiga, diberikan tugas untuk memmbuat makanan, Sang Weda melakukan dengan baik, petunjuk Dang Guru diikutinya, menyebabkan Sang Weda diberi kepandaian berupa Mantra Weda yang utama, berdasarkan atas hasil pembuatan makanannya dinilai baik, setelah selesai dinilai Sang Weda mohon diri untuk pulang".

"Isi berita penting yang datang dari Dang Guru Bhagawan Dhomya itu, supaya muridnya Sang Weda mengikuti beliau berpergian, segala apapun yang ditugaskan oleh Dang Guru Bhagawan Dhomya, semuanya diterima baik oleh Sang Weda yaitu menjaga pasraman dengan isinya, karena akan mengikuti Dang Guru kemudian Sang Weda minta tolong pada muridnya Sang Utangka, yang akan ditugaskan untuk menjaga pesraman, Sang Utangka menerimanya tugas tersebut". 
b) Nilai Pendidikan Subha Asubha Karma

Menurut Ajaran Agama Hindu yang dimaksud dengan subha karma adalah segala perbuatan yang baik, dan asubha karma adalah segala perbuatan yang buruk. Baik buruknya perbuatan akan membawa akibat baik didalam kehidupan sekarang maupun kehidupan yang akan datang. Ajaran agama Hindu selalu memberi saran agar orang selalu mengarahkan hidupnya dengan berbagai persoalan itu menuju kebahagiaan melalui jalan yang baik dan benar (Atmaja, 2010:26). Subha asubha karma ini muncul silih berganti menghampiri kehidupan manusia, oleh sebab itu sangat perlu untuk disadari, diingat dan dilatih sedini mungkin untuk menghindari perbuatan yang tidak baik dan tidak benar. Sebab dan tujuan penjelmaan maanusia ke dunia adalah memang untuk meningkatkan perbuatan ke arah subha karma. Seperti yang disuratkan di dalam Kitab Bhagavadgita Bab III, Sloka 5 berikut ini:

\section{Na hi kascit ksanam api \\ Jatu tisthaty akarma-krtv \\ Karyate hy avasah karma \\ Sarvah prakrti-jair gunaih.}

\section{Terjemahannya:}

Walaupun untuk sesaat tak seorangpun mampu untuk tidak berbuat, karena setiap manusia dibuat tak berdaya oleh hukum alam, yang memaksanya bertindak (Mantik,2007:172).

Dengan menyimak sloka diatas, dapat dipahami bahwa berkarma yang juga berarti berbuat ini merupakan kodrat yang tidak dapat diganggu gugat, umat manusia harus menaati dan menjalankan dengan sepenuh hati dan tentunya dengan sebaik-baiknya agar selalu berada padda jalur subha karma, sebab dengan berbuat baik keadaan sengsara akan terhindarkan. Sehubungan dengan hal tersebut dalam Gaguritan Dang Guru Bhagawan Dhomya, berikut ini adalah kutipan bait yang mengungkapkan subha asubha karma:

"Lemah peteng kaempelang, Dang Guru Ida nyiingakin, Ring Arunika kapica, Antuk baktinyanē langkung, Uddalaka kicen parab, Cening molih, Bagia ne lakar temuang”

(Gaguritan Dang Guru Bhagawan Dhomya, Pupuh Ginada nomor 4 halaman 41-42).

"Utamanyu ngaturang sapariindik, Buta matan titiang, Wit nginum getah Meduri, Dang Guru kalintang sayang”.

(Gaguritan Dang guru Bhagawan Dhomya, Pupuh Maskumambang nomor 14 halaman 51-52).

"Wus punika, Utamanyu kalugrahin, Mantra tamba utama, Dewa Aswino ne yukti, Kaangen mangicalang buta"

(Gaguritan Dang Guru Bhagawan Dhomya, Pupuh Maskumambang nomor 15 halaman 52).

"Nglantur mangkin katureksa, Sang Weda sisya ping tri, Kicen ngaryanang rayunan, Sida ne becik kakardi, Tuntunan Guru Katinutin, Mawinan kicen pangweruh, Mantra Weda mautama, Mlarapan pakardi becik wus punika, Sang Weda mawali budal”. 
(Gaguritan Dang Guru Bhagawan Dhomya, Pupuh Sinom nomor 17 halaman 53-54).

"Kacrita Sang Weda mewali, Ngatonang pasraman melah, Seneng bagia ne Sang Weda, Ring Utangka kapicayang, Mantra Utama ne luhur, Wus nika mapamit budal”.

(Gaguritan Dang Guru Bhagawan Dhomya, Pupuh Smarandhana nomor 21 halaman 59)

\section{Terjemahannya:}

"Siang dang malam pematang sawah yang digenangi air hujan itu dibendung dengan badannya, Dang Guru sebagai penguji menyaksikan kejadian itu, lalu kepada Sang Arunika diberikan hadiah, berdasarkan pada baktinya kepada Dang Guru melebihi, diberikan nama Uddalaka, kamu berhasil, dan akan menemukan kebahagiaan".

"Utamanyu menghaturkan duduk persoalannya, yang mengakibatkan matanya buta, berawal dari minum getah pohon Meduri, Dang Guru mendengarkan hal itu, merasa sangat kasihan dan sayang".

"Setelah itu Utamanyu dianugrahi mantra tamba utama Dewa Aswino, dipakai untuk menghilangkan buta".

"Sekarang dilanjutkan menguji, Sang Weda muridnya yang ke tiga, diberikan tugas untuk memmbuat makanan, Sang Weda melakukan dengan baik, petunjuk Dang Guru diikutinya, menyebabkan Sang Weda diberi kepandaian berupa Mantra Weda yang utama, berdasarkan atas hasil pembuatan makanannya dinilai baik, setelah selesai dinilai Sang Weda mohon diri untuk pulang
"Diceritakan Sang Weda sudah kembali, mendapati pasraman rapi, semuanya tertata dengan rapi, Sang Weda gembira melihatnya, Utangka pun diberikan, Mantra Utama yang luhur, setelah itu Utangka pamit untuk pulang".

Dalam penggalan bait-bait pupuh pada Gaguritan Dang Guru Bhagawan Dhomya tersebut terlihat bahwa sisya atau murid dari Bhagawan Dhomya yaitu Sang Arunika, Sang Utamanyu, dan Sang Weda didalam menjalankan tugas yang diberikan dengan sungguhsungguh mengerjakannya walaupun keliru tidak pernah muridnya tersebut berbohong kepada Dang Guru Bhagawan Dhomya itu termasuk kedalam perbuatan baik atau subha karma dan karena kejujurannya tersebut menjalan tugas mereka pun diberikan hadiah oleh Dang Guru serta dapat membedakan mana perbuatan yang patut untuk dilaksanakan dan mana yang tidak patut untuk dilaksanakan. Tidak ketinggalan juga Sang Utangka yaitu murid dari Sang Weda yang dengan teguh berbakti kepada gurunya saat diberikan tugas menjaga pasraman itu juga perbuatan subha karma karena bisa saja dia berbohong menjaga pasraman tetapi hal itu tidak dilakukannya atas dasar rasa baktinya yang teramat besar.

\section{c) Nilai Pendidikan Tat Twam Asi}

Tat Twam Asi adalah sebuah kata dalam filsafat Hindu yang mengajarkan kesusilaan tanpa batas. Dilihat dari arti kata Tat Twam Asi terdiri dari tiga kata yaitu Tat berarti itu (ia), Twam berarti kamu atau engkau dan Asi berarti adalah. Jadi Tat Twam Asi berarti ia 
adalah kamu atau engkau dan juga saya adalah kamu. Maksud yang terkandung di dalam ajaran Tat Twam Asi ini adalah "ia adalah kamu, saya adalah kamu dan semua mahluk adalah sama", sehingga bila menolong orang lain berarti juga menolong diri sendiri (Atmaja, 2010:53).

Ajaran Tat Twam Asi pada dasarnya berhubungan dengan tuntunan bagi segenap makhluk untuk satu sama lain bisa saling mengasihi, saling menyayangi dan bagi manusia sendiri ajaran ini mengajarkan bahwa terhadap sesama mahluk landasan hubungannya dalam ketergantungan harus didasari atas cinta kasih, sebagai mana mencintai dan menyayangi diri sendiri, demikian pula sebaliknya. Hal ini dinyatakan dalam bait pupuh dalam Gaguritan Dang Guru Bhagawan Dhomya sebagai berikut:

"Anting-anting ne kapica, Sang Utangka manampenin, Ngraris tangkil ring Sang Natha, Jaga mapamit umatur, Tan kalugra durung nunas, Nasi dingin, Gageson nika kapica"

(Gaguritan Dang Guru Bhagawan Dhomya, Pupuh Ginada nomer 32 halaman 70-71).

"Sang Utangka ngamanahan, Pican Sang Natha tan suci, Sang Utangka ngamastuang, Mangda tan polih kapangguh, Kengine gelis maputra, indik niki, Sang Natha Ida Uninga”.

(Gaguritan Dang Guru Bhagawan Dhomya, Pupuh Ginada nomor 33 halaman 71-72).

"Sang Utangka mengampura, Santukan tan kicen mwali, Nulak pastun Sang Utangka, bhuta ne jaga kapangguh, Sang Natha munggah piduka, Pateh kadi ne krasa antuk Utangka".
(Gaguritan Dang Guru Bhagawan Dhomya, Pupuh Ginada nomor 34 halaman 72-73).

"Sang Natha Ida nyawurin, Cening kadi idu geni, Budi suci cangkem mangan, Nirgama kadi samudra, Pada molih panugrahan, yan Sang Ksatria niku, Cangkem succi budi mangan”.

(Gaguritan Dang Guru Bhagawan Dhomya, Pupuh Smarandhana nomor 35 halaman 74-75).

"Pateh-pateh sareng brangti, Pastu tan sida kawaliang, Utangka pamit gageson, Makta anting ne kapica, Tan kocapan maring marga, Pastun Sang Natha Kapangguh, Kapanesan ne krasayang".

(Gaguritan Dang Guru Bhagawan Dhomya, Pupuh Smarandhana nomor 36 halaman 74-75).

\section{Terjemahannya:}

"Anting-anting yang dimohon itu diberikan kepada Sang Utangka, setelah itu menghadap kepada Raja untuk mohon diri pulang, tetapi tidak diijinkan sebelum dapat makanan, lalu diberikan nasi dingin karena didapur belum selesai memasak, dan diberikan secara tergesa-gesa".

"Sang Utangka memikirkan bahwa pemberian makanan berupa nasi dingin dengan tergesa-gesa itu tidak suci, lalu Sang Utangka memberikan kutukan supaya tidak mendapatkan keinginannya untuk cepat mempunyai anak dan tentang hal ini Sang Raja telah mengetahuinya".

"Sang Utangka cepat-cepat memohon maaf, karena tidak diijinkan pulang, Sang Raja menolak kutukan Sang Utangka, agar dalam perjalanan 
pulangnya ketemu dengan para bhuta, karena beliau Sang Raja juga mrasa marah, Kutukan Sang Raja sama dirasakan seperti Kutukan Sang Utangka".

"Ida Sang Raja memberikan jawabannya, kamu Sang Utangka seperti idu geni, budi suci mulut tajam, tak ubahnya sebagai samudra, samasama mendapatkan panugrahan, kalau Sang Ksatria itu mulut suci budi tajam".

"Sang Raja dan Sang Utangka sama-sama marah, masalah kutukan tak dapat dikembalikan, Sang Utangka cepat-cepat mohon diri dengan tergesagesa, sambil membawa anting-anting yang telah diberikan oleh Sang Sawitri”.

Dari kutipan bait pupuh dari Gaguritan Dang Guru Bhagawan Dhomya di atas terlihat jelas nilai Tat Twam Asi terdapat pada bagian dimana Sang Utangka memberikan kutukan kepada Raja Posya karena dianggap memberikan makanan yang tidak suci tetapi hal tersebut diketahui oleh Raja Posya dan mengutuk balik Sang Utangka. Jadi ketika menyaki orang lain dengan perkataan atau perbuatan itu sama saja menyakiti diri sendiri maka dari itu sudah seharusnya wujud nyata dari Tat Twam Asi ini diwujudkan dengan menyayangi, mengasihi dan menolong sesama dan setiap mahluk ciptaan Ida Hyang Widhi Wasa.

Dengan pengulasan tentang halhal tersebut di atas diharapkan yang sudah membaca Gaguritan Dang Guru Bhagawan Dhomya ini mampu mempraktekan ajaran-ajaran serta nilai pendidikan agama Hindu di dalamnya guna mejalani kehidupan agar lebih baik kedepannya.
Kalau kita kaitkan dengan jaman sekarang, dimana dalam Gaguritan Dang Guru Bhagawan Dhomya ini tersirat makna bahwa Dang Guru tidak hanya menekankan ajaran Spiritual saja kepada ketiga muridnya akan tetapi juga mengajarkan tentang pertanian, peternakan dan juga pengolahan. Ketiga hal tersebut yaitu pertanian, peternakan dan pengolahan erat kaitannya dengan kehidupan sehari-hari umat Hindu dimana pertanian berperanan penting dalam kehidupan manusia karena disinilah dihasilkan bahan-bahan pangan serta bahan-bahan papan seperti beras, buah-buahan, sayur-sayuran, kayu dan lain sejenisnya sedangkan dalam bidang peternakan bisa menghasilkan bahan makanan juga berupa daging, telur, susu dan lain sejenisnya serta dalam bidang pengolahan sangat penting karena dalam bidang ini kita dilatih bagaimana mengolah hasil dari pertanian dan peternakan tersebut agar tepat guna serta dapat melestarikan tradisi tersebut karena ketiga hal tersebut juga sangat erat hubungannya dengan acara ritual di Bali yang biasa di sebut Yadnya.

\section{PENUTUP}

Ajaran agama Hindu dalam Gaguritan Dang Guru Bhagawan Dhomya yaitu (1). Ajaran Tattwa yang berkaitan dengan ajaran Panca Sradha dan lebih menekankan pada ajaran Karmaphala Sradha. (2). Ajaran Susila atau Etika yang terdiri dari ajaran Tri Kaya Parisudha. Nilai pendidikan agama Hindu dalam Gaguritan Dang Guru Bhagawan Dhomya yaitu (1). Nilai Pendidikan Asthiti Bhakti yang lebih menekankan kepada Guru Bhakti, (2) Nilai Pendidikan Subha Asubha 
Karma, (3) Nilai Pendidikan Tat Twam Asi.

\section{DAFTAR PUSTAKA}

Agus, Gede Budi Adnyana. 2008. Sisya Bhagawan Domya. Gianyar: Ganda Pura.

Antara, I Gede. 2005. Sastra Bali Purwa, Teori Apresiasi Pribasa Bali Gending Kidung Karya Sastra Cermin Sosial Budaya. Singaraja: FIP. IKIP.

Nada, I Made Atmaja, dkk. 2010. Etika Hindu. Surabaya: Paramita.

Pendit, Nyoman S. 1968. Bhagawadgita. Lembaga
Penyelengaraan Dan Penterjemah Kitab Suci Weda Pada Departemen Agama RI.

Ratnawaty, Latifah, dkk. 202. Struktur Sastra Lisan Aji. Jakarta: Pusat Bahasa Departemen Pendidikan Nasional.

Sanjaya, IGMA. 2002. Mengangkat Nilai-nilai Agama dalam Menghadapi Globalisasi. Surabaya : Paramita.

Suratmini, Ni Wayan. 2010. Sisya Sesana Sebuah Tuntunan Menjadi Siswa Berbudi Luhur. Surabaya: Paramita. 